\title{
Acquisition of clinical skills
}

\section{Linda Gask}

“No-one except you and the patient really know what happens when you take him for an interview. You learn from your own mistakes behind the closed door" (Adams \& Cook, 1984).

Clinical skills in psychiatry are not best acquired in unsupervised practice or in learning by apprenticeship. In the past, it was reported that during the course of their clinical training, students' interviewing skills actually deteriorated rather than improved (Helfer, 1970; Maguire \& Rutter, 1976), although recent research suggests that improved training is now having an impact (Davis \& Nicholaou, 1992). The methods described below may be employed at both undergraduate and postgraduate level. Traditionally, psychiatrists have been actively involved, along with general practitioners, in the provision of communication skills training to undergraduates. In the future, this training will become a continuous process carried out alongside and within other teaching in all specialities (Cushing, 1996). One of the biggest challenges facing medical schools is how to engage and train clinical teachers from a range of specialities in facilitating students in the acquisition of clinical interpersonal skills.

At postgraduate level, teaching focuses on the clinical skills needed to carry out high-quality assessments and provide specialist treatment. Whatever the treatment, it has to be explained to the patient, and his or her cooperation negotiated. A range of basic therapeutic skills is required by any clinician whatever their orientation (see Box 1). Most interview skills training in psychiatry still focuses only on the assessment interview. There is a risk that too much emphasis on the biological aspects of psychiatry will detract from the necessity for attention to human skills. Conversely, formal psychotherapy training may help to develop a trainee's pragmatic understanding of what happens in relationships, but fail to address the routine of the psychiatric out-patient clinic.

\section{The importance of models}

Maguire et al (1978) demonstrated that interview skills training was more effective if undergraduates

Box 1. Basic therapeutic skills

How to engage someone in a clinical conversation

How to help someone to talk freely about their thoughts, feelings, ideas concerns and expectations

How to provide information

How to engage a person in a working treatment alliance of any nature

How to negotiate - this may involve getting a person to stop or start any form of treatment, stop having or start to have medical investigations, and leave or be admitted to hospital

How to help a person change, e.g. stop drinking or engage in some form of rehabilitation for any type of disorder

How to deal with a range of potentially difficult situations where there is, e.g. risk of violence, risk of self-harm, angry relatives

How to be able to talk to families and couples without necessarily being skilled at family therapy

Linda Gask is Senior Lecturer in Psychiatry and Honorary Consultant Psychiatrist at the University of Manchester and Guild Community Health Care Trust (Guild Academic Centre, Royal Preston Hospital, Sharoe Green Lane, Preston PR2 9HT). Her research interests include teaching communication skills, impact of improving mental health skills of primary health care professionals on patient care, quality of mental health care and general practitioner-led purchasing and commissioning. 
were provided with a clear model of what they were expected to achieve. The three-function model developed by Julian Bird and Steven Cohen-Cole (1990) is probably the most comprehensive and highlights three core functions of the interaction between doctor and patient: (a) gathering data to understand the patient; (b) development of rapport and responding to the patient's emotions; and (c) patient education and behavioural management.

Simple outline models for a range of tasks, such as obtaining the history of the presenting complaint, provision of information, breaking bad news and dealing with angry patients, can be developed so that when students come to practise these skills they have a guide from which to work (see Gask, 1998b). This should not only focus on what information to collect (as has been traditional in the psychiatric assessment) but should also pay attention to how to do it and describe the component skills.

\section{Introducing the topic}

Methods useful for introducing the topic are small group discussion, watching taped interviews and videotape modelling.

\section{Small group discussion}

The new developments in problem-based learning should provide an ideal base for tackling and talking about issues of communication when they arise during discussion of particular problems. Discussion can explore the social and psychological impact of illnesses as well as patients' perceptions, knowledge and need for information, and the skills that will be required by the doctor. It is important to ensure that these discussions address not only understanding the patient's problems, but also the impact that a patient might have emotionally on us as health professionals. Group work based around discussion of clinical situations will ideally help students identify the skills that they will need to acquire during the course.

\section{Watching taped interviews}

Observation and discussion of pre-prepared interviews (including your own) can be useful in gently introducing the topic of skills. Discussion can be better focused if sections of the group (no more than two or three in each section) are given different observational tasks (such as 'non-verbal behaviour of the doctor' or 'key verbal cues that the patient offers'). Each section is invited to discuss what feedback they will then offer to the whole group.

If this is one of your own interviews, you can then model the debriefing process by telling the group what you felt that you did well, then how you might have done things differently if you were carrying out the interview again. You can involve the students in commenting on what they think might have improved the interview and introduce the rules of feedback (see Box 2).

\section{Videotape modelling}

There are now several good videotapes which demonstrate skills required in the interview and difficulties that may be met. Teaching departments should have a large selection of such videotapes available when students want to learn specific assessment or management skills. Watching a tape will not on its own lead to behaviour change: an opportunity must also be provided to rehearse the skills using one of the methods described below.

\section{Role-play}

Unlike video feedback, role-play does not allow the interviewer to observe him- or herself directly (unless the interview is also videotaped); however, it does provide opportunity for both giving and receiving personal feedback. The key things to remember when conducting a role-play session are listed in Box 3. There are three main methods, described below.

\section{Group method}

Most teachers employ a method which allows the role-play (either between two students or a student and an actor) to take place in front of a small group of learners who can be employed to:

Box 2. Rules of feedback (from Pendleton et al (1983)

When giving feedback:

Always be positive about the other's performance

Identify the good parts of the interview - be specific about what was good and why

Discuss the parts which could be improved always suggest positive alternatives 
Box 3. Organising a role-play session

Decide what it is that you want to achieve in the role-play (e.g. practising listening skills)

You may wish to prepare a script for the 'patient' or alternatively, to role-play spontaneously a situation which has arisen from a group discussion

Always use the 'patient's' role-name

Make sure that all the participants in the roleplay understand what you (as organiser) want them to do

Allocate an agreed amount of time and stick to it

Ensure that you debrief fully, which may mean allowing people time to come 'out of role'

(a) offer suggestions for alternative ways of conducting the interview

(b) provide suggestions on request from the person conducting the interview; or

(c) supply a replacement interviewer who can attempt to put any suggestions in to effect.

The group members provide feedback to the interviewer and when the interviewee is an actor, he or she can add their own, subjective perception.

\section{Trios}

As above but there is also an observer. He or she is silent throughout the role-play and takes note of the interaction in general and of the specific skills being practised. During feedback, the 'doctor' feeds back first, followed by the 'patient', then the observer. During the session each of the three should take a turn at each role.

\section{Paired role-play}

Useful for learning and practising new skills where there is a specific task and its component skills to learn, such as how to persuade a person to take medication. The session proceeds as follows:

(a) The group works in pairs. One student plays the patient and the other is the health professional.

(b) If there is sufficient time, they should switch over and each play the other part.

(c) The group leader (and helpers if possible; this depends on numbers in the group - ideally no more than one trainer per four pairs) moves around the room between pairs, listening and helping out with useful words and phrases to move the process along.

d) At the end of each turn, both 'doctor' and 'patient' give feedback 'out of role', observing the rules of feedback (see Box 2)

e) At the end of the session, common difficulties experienced and ways of dealing with them are shared and discussed by the group.

Role-play may utilise 'standardised' or 'simulated' patients. A standardised patient is an actor who is trained in a specific role which he or she plays in exactly the same way, irrespective of student factors, and who can provide immediate feedback, usually by moving out of role. Most students find the feedback very helpful but it is important that it is given skilfully. A simulated patient, in contrast, can adapt the responses he or she makes to the student, remaining in role throughout the interview and even during group work. Here, they can make comments 'in the patient's voice' or even replay certain sections from nodal points of the interview with one student after another. Simulated patients are provided with an outline briefing rather than with a script and can provide very intensive feedback on feelings and approaches both in and out of role (Whitehouse et al, 1984). Such 'patients' are trained actors and some can improvise roles according to input from the group prior to the exercise. They may play an important part in training standardised patients in the assessment of students for OSCEs (Objective Structured Clinical Examinations).

Both standardised and simulated patients provide a useful resource for learning new skills, particularly in the management of specific types of patient problem such as 'breaking bad news' or 'talking to the angry patient'.

\section{Taped feedback}

Both videotape and audiotape feedback have been demonstrated to be highly effective in helping undergraduates (Maguire et al, 1978, 1986; Usherwood, 1993) and postgraduates in psychiatry (Maguire et al, 1984; Harrison \& Goldberg, 1993) and other specialities such as paediatrics (Meadow \& Hewitt, 1972) and general practice (Gask et al, 1988; Whewell et al, 1988) to acquire clinical interpersonal skills. Videotape feedback is particularly effective in helping students to appreciate the importance of noticing and using non-verbal communication, but it is a very potent teaching/ learning method and can be detrimental to learners 
if not employed with some sensitivity. It can be experienced as humiliating if not facilitated with some skill. Before any session begins, find out whether the person showing the tape has experienced feedback before so that the group can be engaged in offering support and encouragement if needed.

\section{Consultations to be taped}

Consultations video-recorded for teaching purposes can be conducted with real patients or role-played, with simulated or standardised patients. Audiotaped recordings are particularly useful for routine out-patient interviews where it is not convenient to set up a camera, and in other settings where a videocamera would be too intrusive. All types of recording, if conducted with real patients, require strict adherence to ethical guidelines to ensure confidentiality and informed consent. Facilitation of small groups discussing videotapes at undergraduate level is often most successfully carried out by using joint teaching - to combine the skills of a clinician who teaches the students regularly during the course and a specialist human sciences tutor. At postgraduate level, sessions work best if they are clinically meaningful to participants and utilise not just recordings of assessment interviews in preparation for examinations but also recordings of interviews where trainees are attempting to utilise therapeutic skills (Box 1), both in role-played and real interviews from the out-patient clinic.

There are simple and more complex methods of giving feedback on a recording. In the simple method, the tape can be watched all the way through observing the basic rules of feedback (see Boxes 2 and 4). Videotape and audiotape recordings are particularly useful for enabling us to learn how to recognise key decision points in an interview where there were alternative possible ways of proceeding. In the problem-based method, rehearsal of the actual words that you might use to respond to the patient at such decision points seems to be a particularly useful way of learning new skills (Box 5).

\section{Acquiring group facilitation skills}

Research from both psychiatry (Naji et al 1986) and general practice (Gask et al, 1991) suggests that the best way to learn how to facilitate both undergraduates and postgraduates in the acquisition of skills is by experiential learning - in other words, participating in the group process as a learner along
Box 4. Guidelines for group video feedback: simple method

Sequence of the feedback session

The interviewer says what they think they did well

The interviewee or patient says what the interviewer did well from their perspective (if they are present at the session)

Other observers state what they thought was done well

The interviewer says what they might have done differently to make the interview more effective

The interviewee or patient makes positive suggestions about making the interview more effective (if they are present at the session)

The observer(s) comment on those parts of the interview which could have been done differently; it is important to make positive suggestions about how the interview could have been modified

The interviewer should have the opportunity to say how they feel about the feedback they have received

with others who wish to develop facilitation skills (Bird et al, 1993). This can be followed by either taking a turn at conducting a session and obtaining feedback on your facilitation skills from other group members, or by videotaping yourself conducting a session and watching this in a group of fellow learners in a similar way to that described for watching a consultation (Gask et al, 1992).

\section{Conclusions}

A range of methods can be employed for helping both undergraduates and postgraduate students acquire and develop clinical skills. Basic skills training incorporating tried and tested methods of videotape and audiotape feedback can be followedup with clinical supervision, which focuses not just on what went on during the out-patient consultation, but how it was achieved. The Royal College of General Practitioners has taken the step of introducing video assessment into its membership examination. Should psychiatry be moving in the same direction? 
Box 5. Guidelines for group video feedback: problem-based method (from Gask, 1998a)

\section{Set ground rules}

Useful for taking pressure off person showing tape and putting everyone in the position of 'living' the interview with them: anyone can stop the tape but if they do they must say what they would have done/said differently at that point

Set an agenda

Clarify the purpose of session - fill in background; engage group in asking questions; what does the person showing the tape want from the group?

Provide opportunities for rehearsing new skills Stop the tape regularly at key points and invite rest of group to do so; ask group for comments on what has happened and whether anyone would do things differently; give the person showing the tape the first opportunity to comment; label key skills and strategies that are being utilised on the tape or suggested by the group

\section{Be constructive}

Comment on things done well as frequently as you can without seeming false; comment positively first, followed by things that might have been done differently

\section{Make the group do the work}

Facilitate not demonstrate; summarise suggestions and keep the session flowing; ensure group keeps to the agenda

\section{Conclude positively}

Summarise and ask for feedback from person showing tape and the group; facilitate the development of an action plan for future consultation if this is a real learning goals patient; assist in formulation of new

- Hall, A., Maguire, P., et al (1993) Workshops for consultants on the teaching of clinical communication skills. Medical Education, 27, 181-185.

Cushing, A. (1996) Communication skills. Medical Education, 30, 316-318.

Davis, H. \& Nicholaou, T. (1992) A comparison of the interviewing skills of first- and final-year medical students. Medical Education, 26, 441-447.

Gask, L. (1998a) Small group interactive techniques utilizing videofeedback. International Journal of Psychiatry in Medicine, 28, 97-113.

- (1998b) Psychiatric interviewing. In Companion to Psychiatric Studies (6th edn) (eds A. Zealley, C. Freeman \& E. Johnstone), pp. 233-247. Edinburgh: Churchill Livingstone.

- Goldberg, D., Lesser, A., et al (1988) Improving the psychiatric skills of the general practice trainee; an evaluation of a group training course. Medical Education, 22, 132-138.

- - - Boardman, A. P., et al (1991) Training general practitioners to teach psychiatric interviewing skills: an evaluation of group training. Medical Education, 25, 444451.

- Usherwood, T. \& Standart, S. (1992) Training teachers to teach communication skills: a problem-based approach. Postgraduate Education for General Practice, 3, 92-99.

Harrison, J. \& Goldberg, D. (1993) Improving the interview skills of psychiatry trainees. European Journal of Psychiatry, 7, 31-40.

Helfer, R. E. (1970) An objective comparison of the interviewing skill of freshmen and senior medical students. Paediatrics, 4, 623-627.

Maguire, G. P., Goldberg, D., Hobson, R. F., et al (1984) Evaluating the teaching of a method of psychotherapy. British Journal of Psychiatry, 144, 575-580.

-, Fairburn, S. \& Fletcher, C. (1986). Consultation skills of young doctors: I. Benefits of feedback training in interviewing as students persist: II. Most young doctors are bad at giving information. British Medical Journal, 292, 1537-1578.

Maguire, G. P. \& Rutter, D. R. (1976) History taking by medical students: 1 . Deficiencies in performance. 2 . Evaluation of training programme. Lancet, $i i, 556-60$.

-, Roe, P., Goldberg, D., et al (1978) The value of feedback in teaching interviewing skills to medical students. Psychological Medicine, 8, 697-704.

Meadow, R. \& Hewitt, C. (1972) Teaching communication skills with the help of actresses and videotape simulation. British Journal of Medical Education, 6, 317-322.

Naji, S. A., Maguire, G. P., Fairburn, S. A., et al (1986) Training clinical teachers in psychiatry to teach interviewing skills to medical students. Medical Education, 20, 140-147.

Pendleton, D., Schofield,T., Tate, P., et al (1983) The Consultation: An Approach to Learning and Teaching. Oxford: Oxford University Press.

Usherwood, T. (1993) Subjective and behavioural evaluation of the teaching of patient interviewing skills. Medical Education, 27, 21-27.

Whewell, P. J., Gore, V. A. \& Leach, C. (1988) Training general practitioners to improve their recognition of emotional disturbance in the consultation. Journal of the Royal College of General Practitioners, 38, 259-262.

Whitehouse, C., Morris, P. \& Marks, B. (1984) The role of actors in teaching communication. Medical Education, 18, 262-268.

\section{Appendix}

\section{References}

Adams, G. \& Cook, M. A. (1984) Beginning psychiatry. Psychiatric Bulletin, 8, 53-54.

Bird, J. \& Cohen-Cole, S. A. (1990) The three-function model of the medical interview: an educational device. Advances in Psychosomatic Medicine, 20, 65-88.
The British Universities Film and Video Council ( 55 Greek Street, London W1V 5LR; Tel: 0171734 3687) has a comprehensive database of videotapes. Most universities hold corporate membership. 


\section{Multiple choice questions}

1. Video feedback:

a is unlikely to be helpful for postgraduate trainees

b is effective in enabling undergraduates to acquire new skills

c is particularly useful for learning how to appreciate the importance of verbal and nonverbal communication

$\mathrm{d}$ is inferior to the tried and tested method of learning by apprenticeship

e cannot be used to acquire psychotherapy skills.

2. Role-play:

a always requires the participation of 'simulated' patients

b can be carried out by splitting a group into pairs

c is useful for practising specific tasks

d allows opportunities for students to receive personal feedback

e allows a student the opportunity to observe himself directly.

3. Standardised patients:
a are actors trained in a specific role
b can provide immediate feedback
c must be trained actors
d are a useful resource for Objective Structured Clinical Examinations
e can adapt their responses according to the student's performance.

4. Group work:

a at undergraduate level may be most effective if carried out jointly between a clinician and a specialist human sciences tutor

b facilitation skills can be acquired by training

c facilitation skills can be effectively acquired without having to experience being a member of a group

d skills can be acquired by videotaping your own performance in facilitating a group

e does not require any particular skills.

5. When conducting a group videotape feedback session you should:

a find out whether the person showing the tape has seen him/herself in a group setting before

b encourage the group to be critical

c use the opportunity to demonstrate to the group your own skills as an interviewer

$\mathrm{d}$ give the person showing the tape the first opportunity to comment

e focus on the things that went wrong to ensure that lessons are learned.

\section{MCQ answers}

\begin{tabular}{|c|c|c|c|c|}
\hline 1 & 2 & 3 & 4 & \\
\hline a $F$ & a F & a $T$ & & \\
\hline b $\mathrm{T}$ & b $T$ & b $T$ & & $\mathbf{T}$ \\
\hline$T$ & c $\mathrm{T}$ & c $F$ & & F \\
\hline d F & d $T$ & d T & d & $\mathbf{T}$ \\
\hline e $F$ & e $F$ & e $F$ & e & $F$ \\
\hline
\end{tabular}

